\title{
A REFORMA TRABALHISTA, COM FOCO NO PRINCÍPIO DA SUBORDINAÇÃO, DA BOA-FÉ E DA PROTEÇÃO
}

Luís Henrique Ramos Alves; Alan Rodrigo Bicalho

Universidade do Oeste Paulista - UNOESTE, Curso de Direito, Presidente Prudente, SP. E-mail: luishenrique981@hotmail.com

\section{RESUMO}

A Reforma Trabalhista promulgada em 2017 trouxe inúmeras mudanças na legislação trabalhista que vigia na época. Entre as mudanças há a possibilidade de negociações entre empresas e sindicatos ou empregados. Estas negociações possuem um peso maior comparado com a regra anterior, permitindo até mesmo que esses acordos sobreponham ao legislado. Com isso é possível concluir, que tais negociações poderão não ter uma total eficácia, visto que temos partes desproporcionais dentro da relação de trabalho não sendo possível empregador negociar com empregado por conta da Subordinação. Além disso as partes colocarão seu interesse pessoal acima de tudo, agindo sem ética e, a proteção do empregado fica por fora.

Palavras Chaves: Reforma, Subordinação, Boa-Fé, Protetor, Trabalho.

THE LABOR REFORM, WITH FOCUS ON THE PRINCIPLE OF SUBORDINATION, GOOD FAITH AND PROTECTION

\begin{abstract}
The Labor Reform promulgated in 2017 brought numerous changes in the labor legislation that guarded at the time. Among the changes there is the possibility of negotiations between companies and unions or employees. These negotiations have a greater weight compared to the previous rule, allowing even those agreements to overlap with the legislated. With this we can conclude that such negotiations may not be fully effective, since we have disproportionate parts within the employment relationship and it is not possible for employers to negotiate with employees on account of Subordination. In addition the parties will place their personal interest above all, by acting without ethics, and the protection of the employee is out of the question.
\end{abstract}

Key-words: Reform, Subordination, Good-Faith, Protector, Work. 


\section{INTRODUÇÃO}

No dia 11 de novembro de 2017 entrou em vigor a então reforma trabalhista Lei № 13.467, de 13 de Julho de 2017, trazendo suas mudanças. Com elas, e estudando sobre o assunto me surgiu a seguinte pergunta: A reforma trabalhista permite uma maior negociação entre empregador e empregado? Como essas negociações vão ter uma boa eficácia, uma vez que, o empregado é a parte hipossuficiente da relação e, é a parte subordinada? E a resposta passa, obrigatoriamente, pelo Princípio da Boa Fé. Entretanto, como equilibrar (isonomia) os direitos trabalhistas, ora conquistados ao longo da história, com o referido Princípio, dentro de uma negociação hipossuficiente?

O objetivo deste artigo científico é discorrer sobre a Reforma Trabalhista, o princípio da subordinação, da boa-fé e da proteção.

\section{METODOLOGIA}

O Presente trabalho foi desenvolvido através de um levantamento bibliográfico sobre as modificações da Reforma Trabalhista e sua aplicabilidade dentro dos princípios basilares da relação trabalhista. Para tal, foram utilizados livros e artigos eletrônicos e bibliotecas virtuais, haja vista a escassez de material por conta de a lei ser recente. Para o presente artigo foi se utilizado o método hipotético dedutivo, a partir da análise da legislação vigente e doutrina. É dizer que, buscamos desenvolver hipóteses que podem tornar-se fatos.

\section{RESULTADOS}

Findando-se as análises hipotéticas, resultou-se que a reforma trabalhista poderá trazer, em algumas situações, prejuízo ao empregado dentro da relação de trabalho.

\section{DISCUSSÃO}

\section{ASPECTO HISTÓRICO: SURGIMENTO DA LEGISLAÇÃO TRABALHISTA}

A Legislação Trabalhista surgiu em 1888 com o fim da escravidão, onde havia grandes discussões sobre direitos de trabalhadores e formas de dirimir o conflito que existia entre subordinante e subordinado.

O fim da exploração, da escravidão e as contratações de serviços assalariados, fez crescer os debates sobre direitos trabalhistas o que na época já era muito discutido na Europa que estava vivendo seus dias de Revolução Industrial. Tal revolução foi um divisor de águas na história, pois grandes aspectos da vida cotidiana da época foram influenciados por esse processo, inclusive o Brasil.

O processo de mecanização dos sistemas de produção foi um dos fatores que levou ao desencadeamento dos movimentos em defesa dos trabalhadores. Na medida em que estava havendo a substituição do homem por máquinas e várias pessoas ficando desempregadas.

Neste cenário de Revolução Industrial era comum fábricas funcionarem em situação precária, expondo os trabalhadores a ambientes com escassez de iluminação, mal arejados e sujos, é dizer, insalubres. Os salários eram muito baixos e, grande a exploração de mão de obra chegando a 18 horas a jornada de trabalho.

Com isso, começou a surgir as greves e revoltas sociais. Deu-se início então, as lutas por direitos trabalhistas, surgindo sindicatos que desencadearam movimentos por melhores condições de trabalho. Tais manifestações serviram de inspiração para a formação de movimentos organizados de operários brasileiros.

No Brasil, a primeira tentativa de formação de um Código do Trabalho, de Maurício de Lacerda, é de 1917. No ano seguinte foi criado o Departamento Nacional do Trabalho. E em 1923 surgiu, no âmbito do então Ministério da Agricultura, Indústria e Comércio, o Conselho Nacional do Trabalho. 
Apenas após a Revolução de 1930, com a subida ao poder de Getúlio Vargas, houve o despontamento da Justiça do Trabalho e a proteção dos direitos dos trabalhadores. Em 26 de novembro daquele ano, por meio do Decreto no 19.433, foi criado o Ministério do Trabalho.

A aplicação da Consolidação das Leis do Trabalho, veio com a Constituição de 1934 (artigo122), mas sua regulamentação só ocorreu em 1940 (Decreto 6.596). A Constituição incluiu a Justiça do Trabalho no capítulo "Da Ordem Econômica e Social".

A função a ela atribuída era de resolver os conflitos entre empregadores e empregados. Inicialmente integrada ao Poder Executivo, foi transferida para o Poder Judiciário, o que suscitou acirrados debates entre parlamentares da época, sobretudo no que diz respeito ao seu poder normativo.

A carta constitucional de 1934 trouxe avanços sociais importantes para os trabalhadores: instituiu a jornada de trabalho de oito horas, o salário mínimo, o repouso semanal, as férias anuais remuneradas e a indenização por dispensa sem justa causa.

\section{PRINCÍPIO DA SUBORDINAÇÃO DO EMPREGADO}

Dentro da relação de emprego temos a característica da subordinação. O empregado é subordinado ao seu empregador e este, tem poder diretivo sobre o trabalho do empregado. Há uma subalternidade hierárquica em virtude de que são obrigados a cumprir as ordens e instruções. Além disso dirige, coordena e fiscaliza a prestação dos serviços executados pelos trabalhadores.

\section{PRINCÍPIO DA PROTEÇÃO}

Esse princípio se caracteriza com a interferência do Estado nas relações de trabalho, por meio de normas que buscam compensar uma desigualdade econômica desfavorável ao trabalhador vindo a protegê-lo. Resende (2017, p. 26 e 27) conceitua:

Pode-se dizer que o princípio da proteção consiste na aplicação, ao Direito do Trabalho, do princípio da igualdade em seu aspecto substancial, segundo o qual a igualdade é tratar de forma igual os iguais e de forma desigual os desiguais, na medida de suas desigualdades. Assim, é importante que se tenha em mente que o objetivo principal do Direito do Trabalho é reequilibrar a relação jurídica capital/trabalho (empregador $\mathrm{x}$ empregado) mediante o estabelecimento de mecanismos de proteção à parte mais fraca na relação jurídica.

\section{PRINCÍPIO DA BOA FÉ}

O Princípio da Boa Fé nas relações de trabalho e nas relações de direito real, surgiu por uma intervenção estatal, em parte por uma grande influência de tratados internacionais, que buscavam um maior equilíbrio entre as partes, buscando uma relação harmoniosa entre empregador e empregado.

A Boa-Fé é necessária para que as possíveis situações que surgem dentro da relação de trabalho, possam ter relações harmônicas e leais, para que sejam mantidas e cheguem a uma estabilidade nas relações de trabalho.

É possível dizer que a boa-fé se compõe de regras gerais de condutas impostas pela sociedade como um todo, levando transparência entre as relações, caracterizada como "um dever de agir de acordo com determinados padrões, socialmente recomendados, de correção, lisura e honestidade".

\section{A REFORMA TRABALHISTA}

No ano de 2017 o Brasil passou por uma crise econômica muito forte, o desemprego aumentou e atingiu seu auge em março quando os índices chegaram a 13,6\% o que totaliza 14 milhões de brasileiros desempregados. Com essa grande taxa o governo da Ex-Presidente da República Dilma Rousseff cogitou em realizar uma reforma trabalhista na qual o principal foco 
seria a negociação de questões trabalhistas entre empregadores e empregados. No entanto com muitas pressões sindicais houve a desistência da proposta.

Tendo a presidente sofrido Impeachment, o, até então, Vice-presidente Michel Temer assumiu o cargo e coube a ele dar continuidade a referida Reforma Trabalhista, tendo ela sido promulgada em 2017, trazendo inúmeras mudanças na legislação trabalhista.

Entre as alterações, há a criação do autônomo exclusivo, a terceirização para a atividade principal das empresas, o parcelamento das férias em até três períodos.

Entre outras alterações, destaca-se a possibilidade de grávidas atuarem em ambientes insalubres, atividades de grau médio ou mínimo de insalubridade, onde a gestante deverá ser afastada quando apresentar atestado de saúde de um médico de sua confiança, entretanto não poderão trabalhar em atividades que tenham grau máximo de insalubridade. Pela regra revogada, gestantes e lactantes são proibidas de exercer qualquer atividade insalubre.

Além delas, a negociação da jornada diária, o intervalo intrajornada, a jornada parcial e temporária que poderá ser de 30 horas o que antes era 25 . A nova legislação também visa maiores negociações coletivas para tratar de temas como salário e tamanho da jornada dos trabalhadores e a negociação de questões trabalhistas entre empregadores e empregados.

Dentre as mudanças acima elencadas, as negociações são as que mais chamam atenção, tendo maior foco nesse artigo.

\section{A APLICAÇÃO DA REFORMA TRABALHISTA, A SUBORDINAÇÃO DO EMPREGADO, O PRINCÍPIO DA BOA FÉ E O PRINCÍPIO DO PROTETOR NA SOCIEDADE DO SÉCULO XXI}

Com a entrada em vigor da reforma trabalhista surge um enfoque maior nas negociações entre empresas e sindicatos ou entre empregados, estas negociações possuem um peso maior comparado com a regra anterior, permitindo até mesmo que esses acordos sobreponham ao legislado, entretanto para haver uma boa eficácia nas novas relações é preciso que ambas as partes da relação de trabalho (empregador e empregado) ajam pautados pelo princípio da boa-fé.

Todavia surgem os seguintes questionamentos: como colocar direitos trabalhistas em cima do Princípio da Boa Fé vivendo em uma sociedade que tem perdido de vista esse princípio? Como ter negociações entre Empregador e Empregado se há um vínculo de subordinação entre estes? $\mathrm{E}$ o Princípio do Protetor para proteger a parte hipossuficiente como fica?

No século XXI o princípio da boa-fé vem perdendo proporções onde há possíveis distorções ou ausência dos valores éticos e morais, pois cada sujeito a partir da evolução da sociedade vai incorporando novas atitudes e sentimentos, mantendo, na medida do possível, sua integridade e o seu interesse pessoal.

Essa realidade simulada encontra-se cada vez mais presente em nosso cotidiano. E com isso pode ser que as negociações não venham ter uma máxima eficácia, pois as partes poderão deixar de agir pautadas pela ética e moral.

Com isso é possível que ambos possam vir a colocar o seu interesse pessoal acima de tudo, deixando de lado o princípio da boa-fé contratual. Quando na realidade de acordo com Ricardo Resende (2017, p. 23) "Tanto o empregado quanto o empregador devem agir, em sua relação, pautados pela lealdade e boa-fé".

Além disso, dentro da Reforma Trabalhista há a subordinação do empregado ao empregador, podendo fazer com que as negociações não sejam totalmente eficazes, dentro da relação de emprego temos a característica da subordinação.

O empregado é subordinado ao seu empregador, o empregador tem poder diretivo sobre o trabalho do empregado, há uma subalternidade hierárquica, em virtude do que são obrigados a cumprir as ordens e instruções, além disso dirige, coordena e fiscaliza a prestação dos serviços executados pelo trabalhador. Com isso será que haveria uma verdadeira "Negociação"? 
Essa negociação poderá ser utópica pois imagine a seguinte situação: empregador olha para o empregado e diz, ou você aceita ou está demitido; quem necessita de salário para se alimentar, de maneira implícita não tem poder para negociar, e como consequência acaba aceitando qualquer coisa, é claro que isso é totalmente incoerente pois diante da situação narrada teríamos o empregado cedendo seus direitos ao empregador, por ser a parte hipossuficiente da relação. Diante do exposto é possível pensar, mas e o princípio do protetor? Não teria que proteger a parte hipossuficiente da relação? De acordo com Carla Romar (2014, p. 47):

O princípio do protetor é o critério que oriente todo o Direito do Trabalho e com base no qual as normas jurídicas devem ser elaboradas, interpretadas e aplicadas e as relações jurídicas trabalhistas devem ser desenvolvidas. Este princípio tem por fundamento a proteção do trabalhador enquanto parte economicamente mais fraca da relação de trabalho e visa assegurar uma igualdade jurídica entre os sujeitos da relação, permitindo que se atinja uma isonomia substancial e verdadeira entre eles.

As relações na Legislação Trabalhista têm o Princípio do Protetor que vem nos trazer que a legislação trabalhista tem que criar normas que busquem proteger a parte hipossuficiente da relação de trabalho que no caso seria o empregado. Com a Reforma Trabalhista é possível pensar em uma mitigação do princípio do protetor, uma vez que a própria norma permite a negociação e essa negociação poderá ferir o princípio do protetor por conta do próprio princípio da subordinação e por falta de observância a princípio da boa-fé, com isso é possível que não se tenha a ampliação da proteção, e em vez de se partir para uma evolução da proteção ao empregado, estaríamos na realidade regredindo, com isso essas normas podem ferir essa proteção que demorou tanto tempo para ser conquistada.

\section{CONCLUSÃO}

Analisando-se estão a Reforma Trabalhista sobre o prisma dos princípios basilares da relação de trabalho, é possível concluir-se que, há uma possibilidade do empregado sair prejudicado dentro dessa relação, vez que os cenários descritos mostram de maneira implícita que, em vez de se ter uma amplitude na proteção do empregado teríamos na realidade uma regressão a essa proteção, por conta da boa-fé e da subordinação.

Com a Reforma Trabalhista, há a possibilidade o trabalhador passar a não ter uma proteção legal adequada, e com o passar do tempo poderá acabar sendo transformado em objeto (mercadoria), em "escravo moderno" durante o tempo de trabalho.

Será que a Reforma Trabalhista é compatível com a Dignidade Humana? Seria um meio de Proteção Social? Ou uma Regressão na história do trabalho?

\section{REFERÊNCIAS}

RESENDE, Ricardo. Direito do Trabalho Esquematizado. 7. ed. Rio de Janeiro: Forense; São Paulo: Método, 2017.

ROMAR, Carla Teresa Martins. Direito do Trabalho Esquematizado. 2. ed. São Paulo: Saraiva, 2014.

TRIBUNAL REGIONAL DO TRABALHO DA 24a REGIÃO. História a criação da CLT. Disponível em: <https://trt-24.jusbrasil.com.br/noticias/100474551/historia-a-criacao-da-clt>. Acesso em: 24/02/2018.

RICARDO MARCHESAN. Mudam as Leis do Trabalho: Reforma trabalhista entra em vigor e altera contratação, férias, jornada e até almoço, entre outros. Disponível em: <https://www.uol/economia/especiais/a-reforma-trabalhista.htm\#as-novas-regras-do-jogo>. Acesso em: 02/03/2018. 
BENIGNO NÚÑEZ NOVO. A reforma trabalhista: ausência de um debate amplo com a sociedade. Disponível em: <https://www.direitonet.com.br/artigos/exibir/10484/A-reforma-trabalhistaausencia-de-um-debate-amplo-com-a-sociedade>. Acesso em: 02/03/2018.

O GLOBO. Reforma Trabalhista: entenda as principais mudanças. Disponível em: <https://oglobo.globo.com/economia/reforma-trabalhista-entenda-as-principais-mudancas21194782>. Acesso em: 25/03/2018.

LINDOMAR DA SILVA ARAÚJO. Os Valores éticos nas relações interpessoais no Ciberespaço. Disponível em: <https://www.infoescola.com/sociologia/os-valores-eticos-nas-relacoesinterpessoais-no-ciberespaco/>. Acesso em: 25/03/2018.

VALDETE SOUTO SEVERO. Porque não devemos aplicar a Reforma Trabalhista? Disponível em: <http://justificando.cartacapital.com.br/2017/08/21/por-que-nao-devemos-aplicar-reformatrabalhista/>. Acesso em: 15/04/2018.

VICTOR MALZONI SILVEIRA. A Reforma Trabalhista e seus efeitos no Direito do Trabalho. Disponível em: <https://victormack.jusbrasil.com.br/artigos/441723722/a-reforma-trabalhista-eseus-efeitos-no-direito-do-trabalho>. Acesso em: 03/05/2018.

CARLA CAMPOS. O Princípio da Boa Fé Objetiva -Teorias e Princípios. Disponível em:<http://www.ambitojuridico.com.br/site/?n_link=revista_artigos_leitura\&artigo_id=15478>. Acesso em: 10/05/2018.

CLARINA OLIVEIRA SILVEIRA. O Princípio do Protetor no Direito do Trabalho. Disponível em: $<$ https://www.boletimjuridico.com.br/doutrina/artigo/2196/o-principio-protetor-direitotrabalho>. Acesso em: 10/05/2018. 